\title{
The Vulturine Parrot, Psittrichas fulgidus, a threatened New Guinea endemic: notes on its biology and conservation
}

\author{
ANDREW L. MACK and DEBRA D. WRIGHT
}

\section{Summary}

Vulturine Parrots Psittrichas fulgidus are endemic to the island of New Guinea. A review of the literature and specimen holdings indicate the species mostly occurs 500 to $1800 \mathrm{~m}$ a.s.l. Observations suggest the species occurs in low densities. The species is a highly specialized frugivore feeding on just a few species of figs (Ficus, Moraceae). These parrots are heavily exploited (often by destroying scarce nesting cavities) in Papua New Guinea for their feathers, used in traditional adornment. This practice might not be sustainable and four possible conservation measures are suggested: (1) increase field studies; (2) restrict transport of live birds on domestic flights; (3) replace use of Psittrichas feathers with dyed chicken feathers; (4) instruct tourists not to purchase handicrafts containing Psittrichas or other animal parts.

\section{Introduction}

The Vulturine (or Pesquet's) Parrot, Psittrichas fulgidus, is a monotypic genus endemic to New Guinea. Little is known of the bird's habits. Individuals exhibit little phenotypic geographical variation (Mayr 1937) being mostly drab gray with lighter edging (scalloping) on the edges of chest feathers. The lower chest, belly and underwing coverts, and greater and median wing-coverts are a dramatic red colour; the innermost primary and four outer secondaries are half (lengthwise) black and half red. It is these red feathers, particularly the remiges and primary coverts, that are highly prized for traditional ornamentation by Papuan highlanders. In a recent survey of conservation needs in Papua New Guinea (PNG) (Beehler 1993), the Vulturine Parrot was identified as one of PNG's 12 rarest and most threatened bird species and it is listed as "vulnerable" by BirdLife International (Collar et al. 1994) and on the IUCN Red List (IUCN 1996).

Because Psittrichas feathers are widely used and highly valued for ornamentation and because so little is known of the bird's biology, we have pooled what is known of the species with our field observations in hope of drawing attention to a potential conservation need in New Guinea before the situation becomes urgent. In the light of these data we make four conservation recommendations.

\section{Distribution and density}

We mapped the distribution of Psittrichas from specimen locality data from most major collections, from the literature and from personal communications with 


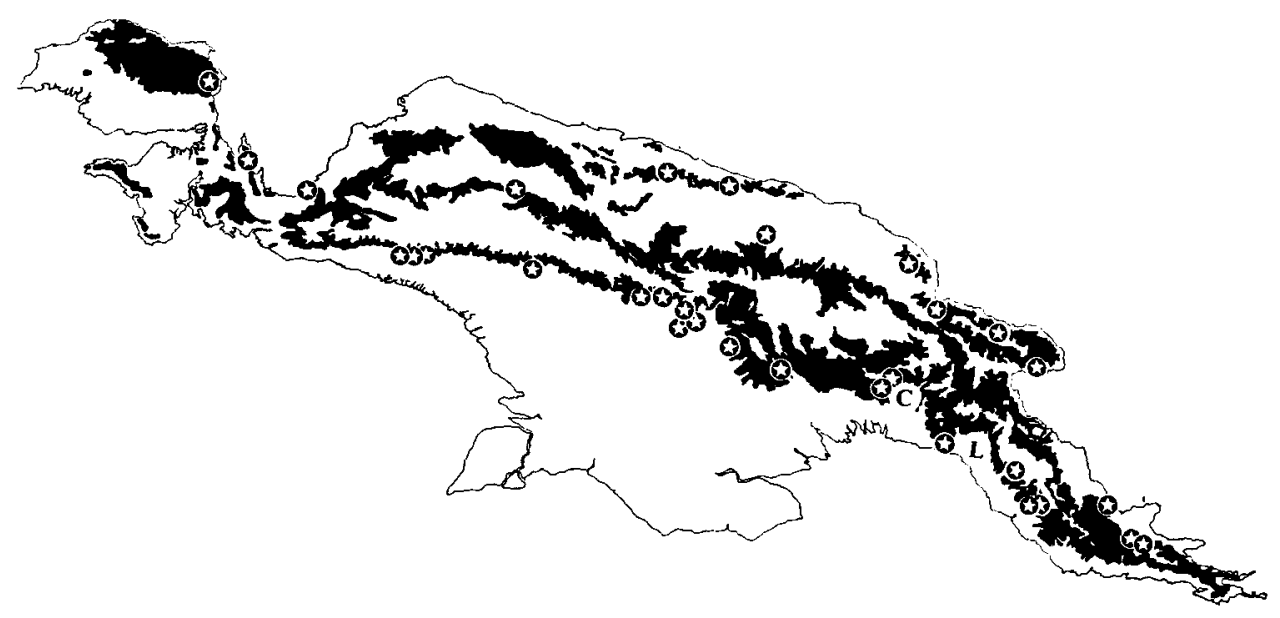

Figure 1. Map of New Guinea showing locations where Psittrichas fulgidus specimens have been collected (circled star symbols). The black areas represent the elevational band between 500 and $2000 \mathrm{~m}$ above sea level. Specimen localities were taken from specimens from the collections listed in the acknowledgments. Letters refer to locations where field observations were made: C, Crater Mountain Biological Research Station; L, Lakekamu Basin.

ornithologists (Figure 1). Almost all records are from within the altitudinal belt 500-1800 $\mathrm{m}$ (Coates 1985, Beehler et al. 1986, Forshaw and Cooper 1989). These records largely coincide with the lower montane forest vegetation zone of Johns (1982) or the hill and lower montane forest of Paijmans (1976). The records from lowland sites (e.g., Pioneer Bivouac $30 \mathrm{~m}$ a.s.l. [Bemmel 1947]; Nomad River $115 \mathrm{~m}$ a.s.1. [Bell 1970]; Wabo, in Crater Mountain Wildlife Management Area, $120 \mathrm{~m}$ a.s.l. [pers. obs.]) were usually close to higher elevations as previously noted (Mayr 1941). However, some birds observed in the Lakekamu Basin (Beehler et al. 1995) were several kilometers from the foothills (C. Burg, pers. comm.). These lowland records probably represent transient individuals, not permanent, extensive lowland populations.

We believe the species is largely dependent upon middle elevations, 500$1800 \mathrm{~m}$ a.s.l. Roughly $180000 \mathrm{~km}^{2}$ lie within the range $500-2000 \mathrm{~m}$ elevation in New Guinea (Figure 1). Despite the growth in use of geographic information systems in conservation, adequate data on forest cover at different altitudes is still not readily available; certainly much of the land between 500-2000 $\mathrm{m}$ elevation is anthropogenically deforested. Based upon coffee production figures, roughly $40000 \mathrm{~km}^{2}$ is devoted to coffee in PNG (Levett and Bala 1994), much of which is grown within the elevational range of Psittrichas. Estimates of clearing due to subsistence farming, the predominant form of agriculture in New Guinea, are difficult to obtain; one estimate puts clearing at $2000 \mathrm{~km}^{2}$ per year in PNG, but it is unknown how much of this is second growth or grassland previous to clearing (Levett and Bala 1994). Extrapolating from these scant data and personal observations during overflights, we conservatively estimate that $20 \%$ of the land in the 500-1800 m elevational belt is strongly modified by people and unsuitable as Psittrichas habitat. 
In PNG roughly $48000 \mathrm{~km}^{2}$ of hill and lower montane forest has been assigned to forestry blocks (Louman and Nicholls 1994) and can be expected to suffer serious degradation. Probably a comparable area is under threat in Irian Jaya, although official figures were not available. Thus in the near future, logging alone could substantially impact roughly half of the forested area within the altitudinal range occupied by Psittrichas.

\section{Population density}

Vulturine Parrots were common at the Crater Mountain Biological Research Station (1o km east of Haia in Chimbu Province, Papua New Guinea, $06^{\circ} 43.4^{\prime} \mathrm{S}$ $145^{\circ} 05.6^{\prime} \mathrm{E}$ ) where field work was conducted October 1989-June 1993. Field observations suggest the daily home range of Psittrichas can be as small as the area enclosing a few fruiting Ficus sp. trees. However, the overall range requirements are certainly much larger; two or three pairs were resident in our study site (c. $14 \mathrm{~km}^{2}$ ). Based on this crude estimate (two pairs $/ 14 \mathrm{~km}^{2}$ ) and the potential habitat in the correct altitudinal range (less $20 \%$ already modified $=144000 \mathrm{~km}^{2}$ ), we estimate the entire population at less than 21 ooo pairs. However, this is a maximum population estimate as (1) the density of Psittrichas food plants at Crater was high relative to other forests we have visited in PNG: (2) Psittrichas were much more numerous around the station than at other sites visited in PNG: and (3) local hunters say Psittrichas were particularly numerous in the study area. Furthermore, Psittrichas were not apparent in our study area for substantial periods, suggesting seasonality and that overall home ranges were larger, probably shifting as different individual Ficus sp. trees come in and out of fruit. Therefore, although the minimum daily home range of $P$ sittrichas might be quite small, the required year-round home range is expected to be much larger (certainly in the thousands of hectares), especially in parts of its distribution where food trees occur at low density.

\section{Diet}

Psittrichas is an extremely specialized frugivore. During four years of fieldwork at Crater Mountain dozens of feeding observations were made; all were of birds feeding upon two varieties of a single species of fig (Ficus sterrocarpa v. sterrocarpa Dielf and v. pubigemma, Section Malvanthera). Local hunters reported that Psittrichas also fed upon one or two fig species (F. trachypison and F. sp. indet.) in the study area, but this was never confirmed by personal observation. The section Malvanthera is comprised of 11-14 species restricted to non-coastal New Guinea and Australia up to $1500 \mathrm{~m}$. All species in the section typically have a distinctive hard receptacle wall (G. Weiblen, pers. comm.).

At Lakekamu in November 1996 we observed Psittrichas feeding upon two different species of figs. A group of up to six birds fed daily at a large fruiting tree: Ficus hesperidiformis King v. myrmekiocarpa (Summerh.) Corner. This species is also in the section Malvanthera and has a hard receptacle wall. A single bird was often observed stopping to feed briefly (10-15 minutes) at another fruiting fig tree just before dusk. This fig, possibly Ficus baeuerlenii King (G. Weiblen, pers. comm.), belonging to the section Rhizocladus, had a more typical, soft and 
fleshy fruit. The Psittrichas at Lakekamu spent several hours per day in and around the $F$. hesperidiformis tree that was fruiting but only lone birds stopped briefly at the F. baeuerlenii tree.

Many weak-billed birds feed upon the figs that Psittrichas open (Mack and Wright 1996), but cannot open the figs themselves. Diamond (1972) observed a similar interaction at nearby Karimui (possibly the same species of Ficus) but with different parrot species opening the figs. Based upon the morphology of pistillate flowers (G. Weiblen, pers. comm.), it appears the weak-billed species consuming the fig interior are the seed dispersers and Psittrichas primarily consume the surrounding fruit pulp. It is possible that Psittrichas plays a complicated role as a keystone mutualist (Daily et al. 1993), opening hard-walled figs (Section Malvanthera) to smaller birds that disperse more seeds than Psittrichas.

At Crater and Lakekamu birds were often observed flying long distances $(>1 \mathrm{~km}$ ) directly to fruiting fig trees or to perches in trees very close to fig trees. Birds fed upon mature figs, filling their crops (visibly distended), then moved to nearby trees where they preened and rested. Breeding birds appeared to return to the area of the nest after feeding rather than remaining near the food tree(s).

Birds are highly vocal; pairs appear to keep in vocal contact across long distances with their loud, grating calls. On several occasions vocal aggressive encounters were observed when other Psittrichas approached occupied fig trees, suggesting pairs sometimes defend fig trees from other Psittrichas. However, up to six birds have been observed in a fruiting tree simultaneously, so resource defense is not constant. Resource defense might vary with breeding condition, fruit availability, or even relatedness of individuals.

Local hunters confirmed that figs are the sole food of Psittrichas. One fieldcollected Psittrichas dropping contained the distinctive remains of Ficus sterrocarpa. Psittrichas were never observed feeding in any of the other $\geq 38$ species of Ficus (unpublished data) found in the Crater Mountain study area despite roughly eight person-years of field time.

The few previously available records of Psittrichas support the prominence of Ficus in the parrots' diet. Two specimens in the CSIRO collections and two at the American Museum of Natural History (Rand 1942a) have figs listed as stomach contents. Schodde and Hitchcock (1968) reported birds eating Ficus in the Lake Kutubu area. Rand and Gilliard (1968) reported figs as the main food item but also stated that large flowers are occasionally consumed. A bird was observed in Western Province feeding at a fig tree that was identical or very similar to F. sterrocarpa (B. Whitney, pers. comm.). A specimen in the CSIRO collection had been observed feeding on flowers of a Myrtaceous tree and two were seen at Freycinetia (Pandanaceae) inflorescences (Rand 1942b).

We are confident Psittrichas is a dietary specialist on just a few species of Ficus. Some flowers are probably eaten, but these alone would be an inadequate diet. This is noteworthy because this might represent one of the most extreme cases of dietary specialization by a frugivore (Ridley 1930, Snow 1981). Figs are well suited for such specialization because of their aseasonal, asynchronous phenology (Janzen 1979). It is interesting to note that captive breeding efforts have found that young Psittrichas die when fed diets normally given to young parrots, but those fed low-protein diets thrive (D. Bruning, pers. comm.). 


\section{Nesting biology}

We found only one active nest; the first Psittrichas nest described in the literature (Mack 1994). The nest was a cavity in a standing, dead tree that was probably enlarged by the breeding pair. Local hunters confirm that large, hollow trees are required for nesting.

\section{Usage by humans}

Vulturine Parrot feathers are highly prized by many highland people for ornamentation (Mayr and Gilliard 1954, Hitchcock 1964, Healey 1976, pers. obs.). Any of the larger red feathers are used, but the 1o coloured remiges are particularly valued. They are often used to make fan-like frontpieces on headdresses. Some of the ornamentation observed at the 1992 Goroka Show was comprised of the wings of at least four Vulturine Parrots (pers. obs.).

We believe the demand for feathers, at least in PNG, is steady or increasing. Annual population growth rate for PNG is estimated at $2.3 \%$; the nation's population is expected to double by 2024 (Gumoi and Sekhran 1994). Traditional dress is still often worn at weddings and other ceremonies. The people of PNG are striving to maintain their cultural heritage through frequent festivals like the Goroka, Hagen, and Madang shows. At these celebrations of culture, tribal groups converge from around the nation to perform in dancing competitions. Groups use traditional adornment and vie for substantial cash prizes. Participants enhance their ornamentation and chances of winning by using more and better-quality feathers. The growing tourism industry in PNG fuels traditional performances for cash. Potentially one unfortunate consequence of competitions and performances is an increase in exploitation of birds bearing ornamental plumes.

In the area of the Crater Mountain Biological Research Station, the native Pawaiian people have little cash income, nor do they traditionally use Psittrichas feathers. With the opening of the airstrip in Haia 20 years ago, these isolated people came in contact with outside tribal groups that purchase Vulturine Parrots. In 1993 a Psittrichas chick could bring 50 Kina (roughly $=\$ 40$ US), a princely sum to a Pawaiian.

The usual means by which Pawaiians obtain Psittrichas chicks is to locate an active nest, monitor it until the chicks are near fledging, then cut down the entire tree or hack open the cavity. The parent birds usually escape unharmed, but the nest cavity is destroyed. This could limit breeding populations because Psittrichas require large, standing trees with rotted centers (Mack 1994) and such trees are rare in the area (pers. obs.). As there are no woodpeckers in New Guinea to excavate cavities, birds are strongly reliant upon naturally occurring cavities. There are many birds, mammals and hymenoptera that typically occupy tree cavities in New Guinea (Coates 1985, 1990, Flannery 1995, pers. obs.). The practice of cutting down hollow trees to obtain prey (other than Psittrichas) in cavities is widespread among Papuan hunters (Dwyer 1974, pers. obs.). Thus the natural low availability of cavities is exacerbated by hunting, intensifying competition among diverse cavity-occupying taxa. 
Chicks acclimate quickly to human surroundings and thrive on a diet of kaukau (sweet potato) and squash. Tamed birds are taken to the highlands by airplane and sold. Thus, even though Pawaiians themselves do not use Psittrichas feathers, the ease of air travel has brought the seemingly insatiable highlands demand for feathers to the cash-starved Pawaiians. The situation in PNG differs in important aspects from the Psittacine conservation problems posed by the international pet trade. (1) Psittrichas are not exported from the country; the demand is entirely domestic. The market is not driven by the exorbitant sums Western aviculturists pay nor can the market be regulated by customs or trade regulations (e.g., CITES). However, in Irian Jaya there is evidence of international trade, but the data are insufficient to estimate its magnitude (Nash 1992). (2) The demand is not entirely for live pets, but for feathers used for decoration. These differences suggest different conservation tactics.

\section{Conservation recommendations}

We believe that there is sufficient cause for concern regarding the conservation status of Vulturine Parrots. The IUCN (1996) classification of "vulnerable" is based upon a declining population projected or suspected in the future based upon habitat conversion or potential levels of exploitation. A projected decline of $20 \%$ in 10 years or three generations (defined as the average age of mature individuals in a population, IUCN 1996) is sufficient for classification as vulnerable. Generation time of Psittrichas is unknown, but based upon scant data from captive birds lifespan could be 20-40 years (D. Bruning, pers. comm.). Given the limited habitat, narrow dietary requirements, hunting pressure, and accelerating forest conversion, we consider the vulnerable status is indeed warranted.

Moreover, much of this concern is equally applicable to other hole-nesting wildlife and animals used for traditional, ornamental purposes in New Guinea. Given these concerns, four feasible recommendations are offered that could have substantial, positive conservation benefits.

\section{Recommendation 1: begin field research}

A study of Psittrichas having three components should be initiated. (1) A survey of Psittrichas feather use and hunting throughout PNG should be conducted. Particular attention should be made to how many birds are harvested and how they are collected (i.e., are nest-trees destroyed), how many feathers are used, whether feather use is increasing, and the geographic origin of feathers. (2) Psittrichas should be censused to estimate total population size. (3) A thorough autecological study should be undertaken. The extreme dietary specialization and the manner in which weaker-billed species rely upon Psittrichas to open figs make this an important system to study for academic/theoretical reasons as well as the obvious conservation applications.

Recommendation 2: restrict transport of live game on airplanes

Regular air traffic to remote regions of New Guinea opens the market for parrots and game of densely populated areas (e.g., the highland's central valley with 
$>1000000$ people) to sparsely inhabited regions (e.g., the traditional Pawaiian lands). This places an insatiable demand from regions where game has been extirpated upon regions where game still exists. Exploitation of these resources for cash will inevitably lead to wider local extirpation, even in areas, such as Pawaiian territory, where local game use could be sustainable. A moratorium on wild animal cargo imposed by the few missionary and commercial airlines serving remote airstrips could have dramatic dividends for wildlife conservation.

National laws restricting trade in wild game in PNG are essentially unenforceable. The transport prohibition proposed could be enforced because pilots have final say in what cargo can be placed aboard their aircraft. Implementing such a moratorium would be difficult and require some time to develop. However, such a moratorium could be developed. For example, several carriers already prohibit transport of alcoholic beverages. At airstrips with a well-enforced moratorium the pressure on animal populations over a wide surrounding area could be substantially reduced. Even with a poorly enforced moratorium, the knowledge that game might not simply go out on the next plane could reduce hunters' motivation.

\section{Recommendation 3: replacement of ornamental feathers}

The diverse cultures of New Guinea should preserve their traditions. Yet, given the rapid growth of PNG's population, it is unlikely that traditional use of wildlife will be sustainable. We propose that carefully crafted imitations should replace traditionally used plumes when practical. The highly-prized red remiges of Vulturine Parrots could be simulated by dyed chicken feathers. A small cottage industry could be developed that trims and dyes feathers to accurately duplicate feathers of many heavily hunted native birds. A readily available, inexpensive, true-looking replicate could undercut the market for feathers of some species, particularly Vulturine Parrots. Admittedly, it would be extremely difficult to copy the extravagant and iridescent plumes of many Birds of Paradise. But there are other exploited species that could be replicated. Before implementing such a program a careful assessment of its implications should be made by anthropologists/ethnologists.

\section{Recommendation 4: educate tourists}

Although regulations forbid the sale of feathers for export (to tourists), police enforcement of these laws is difficult and expensive. Visitors to the PNG highlands are often approached by men selling feathers or trinkets adorned with feathers (pers. obs.). An effective alternative to enforcement is to distribute pamphlets in all tourist hotels and lodges (a fairly small number in PNG) urging tourists not to purchase items containing animal parts. Such a pamphlet should be in several languages, illustrate examples of illegal items, explain the impact of such items on wildlife populations, and emphasize the illegality of such purchases. The pamphlet should urge tourists instead to invest in the exquisite native handicrafts produced in the country that do not contain animal parts.

We have described a situation where an intriguing endemic to New Guinea could be seriously threatened. Moreover, through the potentially important eco- 
logical role of Psittrichas and the impact of its exploitation (loss of nest cavities), the threat ramifies to other species. The four conservation recommendations would be effective and relatively inexpensive. The implementation of these recommendations could not only benefit Psittrichas, but would benefit many wildlife species in New Guinea.

\section{Acknowledgments}

Field work at Crater Mountain was mainly supported by NYZS/The Wildlife Conservation Society and grants from the National Science Foundation, the Douroucouli Foundation, the World Nature Association and a Fulbright travel grant. Fieldwork at Lakekamu was supported by Conservation International and a grant from USAID. We thank the Pawaiian, Gimi and Kamea people for their hospitality and assistance in the field; the University of PNG Biology Department for sponsoring us; Pacific Helicopters, Mal and Christine Smith, Jack and Isa Douglas, Rus \& Ruth Mack, and Bob Park for logistical and moral support. Peter Burke, Phillipa Eckhart, Chris Filardi, Hector Gomez, Brian Kennedy, Heinrich Jessen and Ross Sinclair assisted with fieldwork. George Weiblen kindly identified fig voucher specimens; he and Doyle McKey discussed many aspects of fig biology with us.

The following scientists assisted by providing data drawn from their collections or personal observations: Mark P. Adams (The Natural History Museum, Tring), David Agro (Academy of Natural Sciences), Allen Allison (Bernice P. Bishop Museum), Walter Boles (Australian Museum), Frank Bonaccorso (PNG National Museum), Chuck Burg, Betsey Cutler (California Academy of Sciences), Rene Dekker (National Natuurhistorisch Museum) Carla Dove (U. S. National Museum of Natural History), Philippa Horton (South Australian Museum), Ron Johnston (Western Australian Museum), Mary LeCroy (American Museum of Natural History), N. W. Longmore (Queensland Museum), Raymond A. Paynter, Jr. (Museum of Comparative Zoology), Bill Peckover, Richard Schodde (Australian National Wildlife Collection, CSIRO), Bret Whitney, and David Willard (Field Museum of Natural History).

\section{References}

Beehler, B. M. (1993) Biodiversity and conservation of the warm-blooded vertebrates of Papua New Guinea. Pp. 77-155 in B. M. Beehler, ed. Papua New Guinea Conservation Needs Assessment, vol. 2 Washington, D.C.: Biodiversity Support Program.

Beehler, B. M., Pratt, T. K. and Zimmerman, D. A. (1986) Birds of New Guinea. Princeton, New Jersey: Princeton University Press.

Beehler, B. M., Sengo, J. B., Filardi, C. and Merg, K. (1995) Documenting the lowland rainforest avifauna in Papua New Guinea - effects of patchy distributions, survey effort and methodology. Еmu 95: 149-16r.

Bell, H. L. (1970) Field notes on birds of the Nomad River subdistrict, Papua. Emu 70: 97104.

Bemmel, A. C. V. van. (1947) Two small collections of New Guinea Birds. Treubia 19: 1-45.

Coates, B. J. (1985) Birds of Papua New Guinea vol. 1: Non-passerines. Alderley, Queensland: Dove Publications. 
Coates, B. J. (1990) Birds of Papua New Guinea vol 2.: Passerines. Alderley, Queensland: Dove Publications.

Collar, N. J., Crosby, M. J. and Stattersfield, A. J. (1994) Birds to watch 2: The world list of threatened birds. Cambridge, U.K.: BirdLife International. (BirdLife Conservation Series vol. 4.)

Daily, G. C., Ehrlich, P. R. and Haddad, N. M. (1993) Double keystone bird in a keystone species complex. Proc. Natl. Acad. Sci. U.S.A. 90: 592-594.

Diamond, J. M. (1972) Avifauna of the eastern highlands of New Guinea. Publications of the Nuttall Ornithological Club, vol. 12. Cambridge, Massachusetts: Nuttall Ornithological Club.

Dwyer, P. D. (1974) The price of protein: five hundred hours of hunting in the New Guinea highlands. Oceania 44: 278-293.

Flannery, T. F. (1995) Mammals of New Guinea. Ithaca, New York: Cornell University Press.

Forshaw, J. T. and Cooper, W. T. (1989) Parrots of the World. Third edition. Willoughby, Australia: Kevin Weldon and Associates.

Gumoi, M. and Sekhran, N (1994) An overview of the Papua New Guinean economy: the implications for conservation. Pp. 41-57 in Sekhran, N. and Miller, S., eds. Papua New Guinea country study on biological diversity. A report to the United Nations Environmental Program. Waigani, Papua New Guinea: Department of Environment and Conservation, Conservation Resource Centre; and Nairobi, Kenya: Africa Centre for Resources and Environment.

Healey, C. J. (1976) Exploitation of birds of paradise in the Bismarck Mountains of Papua New Guinea. PNG Bird Society Newsletter 116.

Hitchcock, W. B. (1964) An introduction to the natural history of a New Guinea highland community. Emu 63: 351-372.

IUCN (1996) IUCN Red List of threatened animals. Gland, Switzerland: IUCN.

Janzen, D. H. (1979) How to be a fig. Ann. Rev. Ecol. Syst. 10: 13-51.

Johns, R. J. (1982) Vegetation zones. Pp. 309-330 in J. L. Gressitt, ed. Biogeography and Ecology of New Guinea. The Hague: Dr W. Junk.

Levett, M. and Bala, A. (1994) Agriculture in Papua New Guinea. Pp. 125-153 in Sekhran, N. and Miller, S., eds. Papua New Guinea country study on biological diversity. A report to the United Nations Environmental Program. Waigani, Papua New Guinea: Department of Environment and Conservation, Conservation Resource Centre; and Nairobi, Kenya: Africa Centre for Resources and Environment.

Louman, B. and Nicholls, S. (1994) Forestry in Papua New Guinea. Pp. 155-167 in Sekhran, N. and Miller, S., eds. Papua New Guinea country study on biological diversity. A report to the United Nations Environmental Program. Waigani, Papua New Guinea: Department of Environment and Conservation, Conservation Resource Centre; and Nairobi, Kenya: Africa Centre for Resources and Environment.

Mack, A. L. (1994) Notes on the nests and eggs of some birds at the Crater Mountain Research Station, Papua New Guinea. Bull. Brit. Orn. Club 114: 176-181.

Mack, A. L. and Wright, D. D. (1996) Notes on the occurrence and feeding of birds at the Crater Mountain Biological Research Station, Papua New Guinea. Emu 96: 89-101.

Mayr, E. (1937) Birds collected during the Whitney South Sea expedition. XXXVI. Amer. Mus. Novit. 947.

Mayr, E. (1941) List of New Guinea Birds. New York: American Museum of Natural History.

Mayr, E., and Gilliard, E. T. (1954) Results of the American Museum of Natural History expeditions to New Guinea in 1950 and 1952. Bull. Amer. Mus. Nat. Hist. 103: 311-374.

Nash, S. V. (1992) Parrot trade records for Irian Jaya, Indonesia, 1985-1990. TRAFFIC Bull. 13: 42-45.

Paijmans, K. (ed.) (1976) New Guinea vegetation. Canberra, Australia: Australian National University Press. 
Rand, A. L. (1942a) Results of the Archbold Expeditions. No. 42. Birds of the 1936-1937 New Guinea Expedition. Bull. Amer. Mus. Nat. Hist. 79: 289-366.

Rand, A. L. (1942b) Results of the Archbold Expeditions. No. 43. Birds of the 1938-1939 New Guinea Expedition. Bull. Amer. Mus. Nat. Hist. 79: 425-516.

Rand, A. L., and Gilliard, E. T. (1968) Handbook of New Guinea birds. New York: American Museum of Natural History.

Ridley, H. N. (1930) The dispersal of plants throughout the world. Ashford, Kent, U.K.: L. Reeve.

Schodde, R., and Hitchcock, W. B. (1968) Contributions to Papuasian ornithology. I. Report on the birds of the Lake Kutubu Area, Territory of Papua and New Guinea. Div. Wildlife Res. Tech. Paper 13: 1-73.

Snow, D. W. (1981) Tropical frugivorous birds and their food plants: a world survey. Biotropica 13: 1-14.

ANDREW L. MACK

Conservation International, Rapid Assessment Program, c/o P. O. Box 15, Weikert, PA 17885 U.S.A.

e-mail:a.mack@conservation.org

DEBRA D. WRIGHT

P.O. Box 15 Weikert, PA 17885 U.S.A.

e-mail: ddwright@ptd.net 